\title{
Entrepreneurial Orientation and its Dimensions Impact on Firms Performance with the Mediating role of Innovation Performance
}

\author{
Yasmeen Sultan*1, Sualeh Khattak2 ${ }^{2}$ \& Habib Ahmed ${ }^{3}$ \\ 1,2,3 Hamdard University, Islamabad, Pakistan
}

\begin{abstract}
The Entrepreneurial Orientation (EO) of firms is broadly described as a dimension of strategic posture and important part for enhancing firm Performance. The current study investigated the effect of Entrepreneurial orientation and its dimensional factors (Innovativeness, Risk-taking, Pro-activeness, Competitive Aggressiveness and Autonomy) on firm Performance with the mediating effect of Innovation Performance. Based on data from SMEs, the results indicated that EO has a significant positive association with firm execution. First, Entrepreneurial orientation focus on grown-up economy was expanded, taking a step in the direction of the applicability of the Entrepreneurial Orientation idea in the growing economy perspective. Second, it was explored how Innovation performance connected with SMEs performance and competitive power control the association between entrepreneurial orientation and firm performance. The most important objectives of these studies are to establish the level of Entrepreneurial Orientation on SME and create the influence of this orientation on firms performance. The Research study also represents policy and practice that give a source for entrepreneurial orientation decision and actions. In other words, it was established that EO helps SMEs owners to act entrepreneurially.
\end{abstract}

\section{Introduction}

The Small \& Medium Enterprise (SME) plays an essential function in Pakistan monetary growth. Worth of small and medium enterprises and entrepreneurship to countries "economies has significance gain; huge firms in an attempt to stay behind beneficial are implementing mass lay-offs on non-core sector of their big business (Van Gelderen et al., 2005). In the same way, a number of scholars recognize and appreciate the significant role played through Small \& medium enterprises as engines for powerful financial development and improvement. The helpful welfare and competitiveness of most economies, both nationally and internationally depends to a large degree with the universal health of SMEs of Pakistan. For example, in US $85 \%$ of new jobs are generated by SMEs (Audretsch, 2002; Lappalainen and Niskanen, 2009). When Small \& Medium Enterprises and entrepreneurial orientation contributed more into economic growth, the study of how this business and entrepreneurs in general can improve their performance to warranty their continued existence in the harsh economic environment has become even more important. In the Most Research studies Entrepreneurship literature implies useful concept that would be operated when investigating for potential reparations or enhance their businesss chances during unsympathetic economic times.

*Corresponding author.

Email: yasmeensultan291@gmail.com
This study is grounded on the two theories, i.e. Resource Based theory and Schumpeter Innovation Theory. Resource based theory explains the creation of market place vision to contain feature (Alvarez and Busenitz, 2001). It also suggests that Organization wishes to achieve greater than standard profits by implementing certain factors. Advertise system must be continually better educated concerning the future worth of these Mythologies than further firms in the similar market (Alvarez and Barney, 2004).

Schumpeter Innovation theory (Schumpeter, 1939) established the role played by innovativeness performance in entrepreneurial orientation; it describes a process, procedure of development and of creative destruction which happens when existing market structures are interrupted by new goods and services development process that move resources away from existing business to new ones consequential to wealth creation through establishments of new firms.

\subsection{Problem statement}

Given the high disappointment rate of small firms in Pakistan, there is a need to recognize system \& get better performance. As indicated by Giampiccoli et al. (2013), Entrepreneurial Orientation is a critical way to obtain competitive advantage and enhance performance for a wide range of firms. Different Investiga- 
tions have demonstrated a positive connection between the usage of entrepreneurial orientated procedures and company Performance (Covin et al., 2006; Marfo et al., 2015; Rose, 2007; Short et al., 2009; Wang, 2008). This suggests that in new small businesses; firms implement entrepreneurial orientated approaches and carry on entrepreneurially orientated method, and the more effective they are probably going to be. Very few small firms, on the other hand, take on entrepreneurial orientated activities (Zehir et al., 2015).

\subsection{Research Gap / Finding}

The research gap in this study is that, in base article the researchers have taken only three measurement dimensions of Entrepreneurial Orientation (Innovativeness, Pro-activeness, \& Risk-Taking) to measure firm performance (SMEs). But current study takes five measurement dimensions of Entrepreneurial Orientation (Innovativeness, Pro-activeness, Risk Taking, Autonomy, and Competitive Aggressiveness) to measure firm performance (SMEs) with the mediating role of Innovation Performance in Islamabad Pakistan. Beside this, the majority of the studies with one exception (Hughes and Morgan, 2007), have only precise Entrepreneurial Orientation and have not checked the connection of its individual dimensions and firm performance. The current study aims to check the individual impacts on the firm performance of SME. In other words, it was established that EO helps SMEs owners to act entrepreneurially. This research study thus intends to fill up this research gap. The limited growth of SMEs in Pakistan and their high failure rate may be associated with them lacking the entrepreneurial orientation and its dimensions needed.

\section{Literature Review}

\subsection{Entrepreneurial Orientation}

First of all, the idea of Entrepreneurial Orientation was developed by Miller (1983), then by Covin et al. (2006), which is based on the three dimensions of Entrepreneurial Orientation (i.e., Innovativeness, Proactiveness, and Risk-Taking). In the Past literatures the research has shown a direct connection between Entrepreneurial Orientation (EO) and firm Performance (Bengesi and Le Roux, 2014; Lee et al., 2001; Lumpkin and Dess, 1996; Zahra and Covin, 1993). On the other hand, the important deliberation remains around the part of entrepreneurial orientation (Covin et al., 2006). Lumpkin and Dess (1996) also paid attention to the complexity of entrepreneurial orientation to Firm performance and proposed that the affiliation between entrepreneurial orientation (EO) and Firms performance connection is precise. On the other hand, the relation- ship between entrepreneurial orientation and firm performance is affected by external factors as well as internal factors of firms. The entrepreneurial orientation research study has been mostly conducted in United States or other developed countries.

\subsubsection{Innovativeness}

Innovativeness in a firm is defined as the introduction of novel ideas that can allow the firms to develop its product or service. Mirela (2008) established that innovativeness is a very important aspect for survival, development, performance, growth, and successful firms.

\subsubsection{Pro-Activeness}

First of all, the concept of Pro-activeness was defined by Rauch et al. (2004), he explained it as an opportunity seeking and forward-looking insight characterize through the beginning of new goods and services process in advance of the competition and performing best in expectation for future demand.

\subsubsection{Risk-Taking}

Risk taking is the most important third dimension of Entrepreneurial Orientation. According to Miller and Friesen (1982) the risk-taking is described or defined as the measure of firms in which manager is ready to create huge and risky source faithfulness, to support, those which have a reasonable option of special stop working". In this study the purpose of risk taking in entrepreneurial orientation may be recognized because it is incented replace of entrepreneurial orientation.

\subsubsection{Autonomy}

According to Lumpkin and Dess (1996) the entrepreneurial Orientation dimension of Autonomy is defined as the firms tendency in the direction of independence or self-sufficiency, which is a key element of entrepreneurial orientation.

\subsubsection{Competitive aggressiveness}

According to Lumpkin and Dess (1996) the Competitive aggressiveness dimension of entrepreneurial orientation is referred as a firms tendency to straight and powerfully challenge its competitor to accomplish ingress or obtain improved location in the marketplace and is characterize by receptiveness in situation of argument or reactive action.

\subsection{Firm Performance of SMEs}

In todays big business world, firm performance is considered very vital. On the other hand, a lot of principle use in research studies which determines firm performance of Small \& medium enterprises. According to 
Venkatraman and Ramanujam (1986), the firm performance of SMEs can be measured with both dimensions which are financial performance and non-financial performance of a firms. Financial measures are basically related to monetary factors such as profitability and sales expansion of firms or organization. For Example: return on assets (ROA) and return on sales (ROS) and non-financial measures are related to products, services quality, employees and customers satisfaction. In fact, they have confidential firm performance data is one dimension.

\subsection{Innovation Performance}

Innovation performance can be defined as the utilization of an ideas or creativity, which is used to improve the products, processes, procedures that increase the significance of firm performance and usefulness of the products and services of firms. Innovation performance is a vital factor for the firm performance which includes both terms (financial or non-financial performance) and evaluates competitive advantage of firms (Bhuian et al., 2005). In this research study the mediating variable Innovation performance is used to measure direct impact on firm performance.

\subsection{Relationship between Innovativeness and Firm Performance}

Innovativeness is first and most important dimension of entrepreneurial orientation that explains the thoughts which support creativity for goods / services development, introductions of technologies in their process and procedures, and products / services novelty through research and development (Lumpkin and Dess, 2001). Innovativeness occurs when an innovative firm is willing to try new product line \& experiment with a new advertising, to an obsessive obligation in new products or technological (Lumpkin and Dess, 1996). According to Wiklund and Shepherd (2005) the innovativeness emphasizes on a high-performance rate to firm performance, in current market situations.

$H_{1}$ : Innovativeness has positive significance influence on firm performance and direct impact on its measures.

\subsection{Relationship between Pro-Activeness \& FP}

Pro-activeness is a second dimension of entrepreneurial orientation and its can be described as the firms proactive or reactive activities towards their competitor. According to Lumpkin and Dess (1996), Proactiveness can also improve firm performance which includes financial or non-financial performance, which increases competitive advantage of a firm. The significance of pro-activeness is highlighted in theoretical and empirical research dissuasions. On theoretical level, the pro-activeness leads to increased firm performance. On empirically level the pro-activeness leads to better performance in terms of financial or non-financial which is growth and profitability, products and services firm performance (Kraus et al., 2011).

$\mathrm{H}_{2}$ : Pro-activeness has positive significance influences on firm performance and directly impacts its measures.

\subsection{Relationship between Risk Taking and Firm Performance}

Risk taking is related to independent action of an individual or group of members to bring novelty of dreams and then forwards an idea or a vision and carrying it out to completion (Lumpkin and Dess, 1996). The significance of risk taking and its impacts on firm performance also highlighted in theoretical and empirical research discussions. Literature suggests that firms willingness to engage in high risk-taking behavior which enables firm to seize profitability opportunities of uncertainty leads to long term profitability (McClelland, 1961). Similarly, empirical studies suggest that the risk-taking enables firms to secure superior growth and long-term profitability in contrast to risk avoiders.

$\mathrm{H}_{3}$ : Risk taking has positive significance influences on firm performance and directly impacts on its measures.

\subsection{Relationship between Competitive Ag- gressiveness and Firm Performance}

Competitive aggressiveness requires strong accomplishment with the intention of outperforming industry rivals. This can be ended by improving current products development as well as doing things differently. According to Kollmann and Stöckmann (2014) Firms as a result discover a new position for themselves or target at the competitors weaknesses by increasing superior products or services. Additionally, firms can act insistently and rapidly through innovation. Competitive aggressiveness mobilizes constant participant evaluation further more as a result the deconstruction of the worth parcels of the rivals to produce greater contributions Hughes and Morgan (2007).

$\mathrm{H}_{4}$ : Competitive aggressiveness has positive significance influences on firm performance and directly impacts on its measures. 


\subsection{Relationship between Autonomy and firm Performance}

Autonomy encourages innovation because it is a cause for creativeness and idea. Entrepreneurial orientation initiative is altered in entrepreneurial outcome by independent hard work of key individuals performing external control (Lumpkin and Dess, 2001). Such individuals are frequently referred to as champions (Green et al., 2008). Firms member that desires to investigate speculation opportunities repeatedly should generate environment, where novelty group members are open to survey potential not including the pressure of planned norm or managerial civilization that may slow down the detection process (Burgelman, 1983). We therefore anticipate that autonomy influences the SMEs performance.

$H_{5}$ : Autonomy has positive significance influence on firm performance with directly impacts on its measures.

\subsection{Relationship between Entrepreneurial Orientation \& Innovation Performance}

Current study is supported by two theories, which include Schumpeterian innovation theory for firms performance two dimensions financial or non-financial performance, and second is resource-based theory. So, Schumpeter Innovation theory is for entrepreneurial orientation and its five dimensions which are Innovativeness, Pro-activeness, risk taking, competitive aggressiveness and autonomy. Whereas the Resource based theory provides a powerful impact to organizations and how they can perform better than other firms which are existing in the same market.

$H_{6}$ : Entrepreneurial Orientation has positive significance influence on Innovation performance.

\subsection{Innovation Performance Mediate the relationship between (EO) \& (FP)}

In the strategy literature innovation performance is an important concept that creates value for SMEs and enables sustainable competitive advantage in the complex and rapidly changing business environment (Madhavan and Grover, 1998). Firms that have higher innovation capabilities are more successful in responding to changing conditions and developing new capabilities to adopt changes and as a result achieve better performance (Fernández-Muñiz et al., 2009). Innovation performance is related to organizations adoption of a new idea or behavior (Zaltman, 1973). Innovation occurs in different types such as product innovation, process innovation, service innovation and technological innovation. Therefore, due to the intense competitive environment, firms need entrepreneurially ori- ented individuals or groups in order to innovate new and different products, services, images and processes which cannot be imitated easily by others. This is why we propose that innovation Performance mediates the positive relationship between EO \& FP.

$H_{7}$ : Innovation performance positively mediates the relationship between Entrepreneurial orientation and its dimensions with directly impact on firms performance and its measures.

\subsection{Relationship between Entrepreneurial Orientation, Innovation Performance \& Firm Performance}

The relationship between Entrepreneurial Orientation and its dimensions impact on firm performance is a vital focus in this research (do Paço et al., 2011). On the other hand, various studies have shown that Entrepreneurial orientation has a positive relationship directly or indirectly with firm performance which could be financial or non-financial performance. It means that Small \& Medium Enterprises that adopt Entrepreneurial orientation and its dimensions outperform. Entrepreneurial Orientation and its dimension have been one of the most significant factors which show a competitive advantage.

$\mathrm{H}_{8}$ : Entrepreneurial Orientation and Innovation Performance both have significant and positive impact on firm performance.

\section{Methodology}

\subsection{Research Design}

This Research design is arrangement of conditions for collection of data and analysis of data relevant to research purpose with economy technique (Kothari, 2004). This study will adopt a descriptive research design.

\subsection{Population}

The target population under this study is registered SMEs in Pakistan County. This contained a total of all the 250 registered SMEs with Premier institution of the Government Pakistan under Ministry of Industries \& Production. Small \& Medium Enterprises development Authority (SMEDA) was established in October 1998.

\subsection{Sample Design}

This study used a random sampling process to select the target population of the research study. A sample size (10\% to $30 \%)$ is good representation of selected and target population (Mugenda and Mugenda, 2003). 


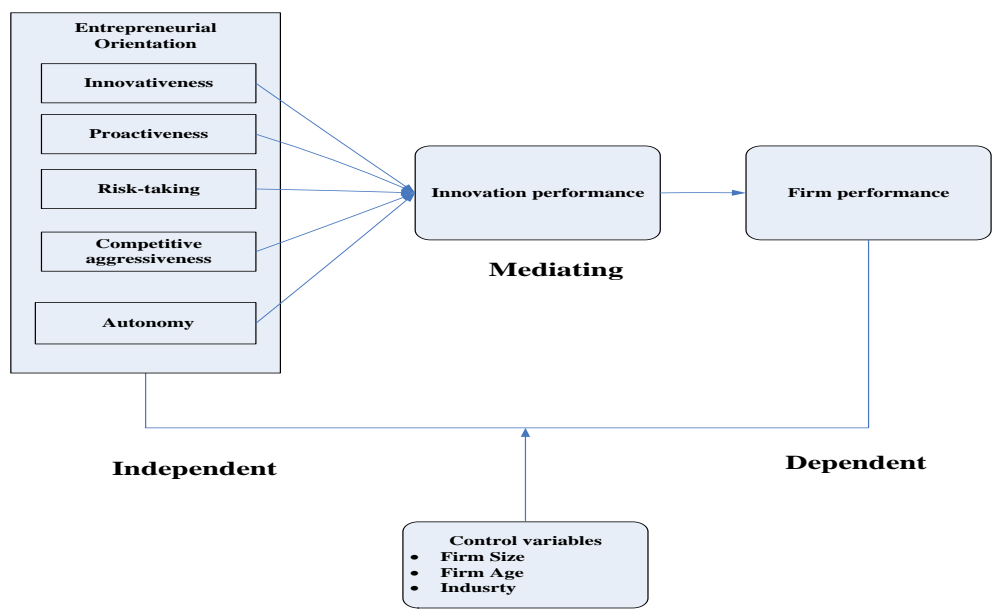

Figure 1: Theoretical Framework

The sample size of this study was 250 SME in Pakistan. The sampling frame included either services or manufacturing industries.

\subsection{Data Collection}

The study has been used primary data collected using questionnaires. Questionnaires are a quick method of obtaining data as compared to other instruments. To achieve this purpose the researcher sustained an evidence of questionnaires. The questionnaires were administered using a drop and pick technique to SMEs owners \& managers .In this research study the independent variable dependent variables and mediating variable require five-point Likert-scale responses ranged from $(1)=$ strongly disagree, $(2)=$ disagree, $(3)=$ neutral, (4) = agree and (5) = strongly agree.

\subsection{Instrumentation}

\subsubsection{Independent Variables}

Entrepreneurial orientation in this study is used as independent variable. Scale developed by (Lumpkin and Dess, 1996) was adopted for measuring (EO). Fifteen items were used for five Entrepreneurial orientation dimensions with Five-point Likert scale by Covin and Slevin (1989). Where (1) = strongly Disagree, $(2)=$ Disagree, (3) = Neutral, (4) = agree, (5) = strongly agree. All the questions in the survey were used to measure the firms performance and measure firm activities.

\subsubsection{Dependent Variable}

The dependent variable of this research study is firm performance. To measure performance, the first one is financial firm performance and the second one is non-financial firm performance. General Managers of the firms were requested to rate their financial and nonfinancial performance over the past three years as com- pared to their competing firms. İşeri-Say et al. (2008) business performance scale was used. So financial performance was measured concentrating on growth and profitability which involves three questions where as non-financial performance was measured concentrating on customer and employee outcomes which involve four items scale. Firm performance measure with total seven item scale, on a 5-point Likert scale, where (1) = very low,$(2)=$ low,$(3)=$ moderate,$(4)=$ high, and (5) $=$ very high.

\subsubsection{Mediating Variable}

The Mediating variable of this study is Innovation Performance. Scale developed by Prajogo and Sohal (2006) was used to measure innovation performance. On the other hand, accordingly to West and Anderson (1996) the concept of innovation performance is defined as the application of new ideas, processes or procedures. The 6-items questionnaire is created to measure innovation performance, with five-point Likert scales, where (1) = strongly disagree, $(2)=$ disagree, (3) = neutral, (4) = Agree, and (5) = strongly agree are used to get responses from SMEs owners.

\section{Results}

\subsection{Tests of Reliability and Validity}

In this study we used a test of Reliability (consistency) and validity to measure the internal consistency of variables items. In the test of reliability and validity we evaluate the internal consistency of variables items which is estimated by using Cronbachs Alpha value. So that the results of this study analysis were as shown in(Table-1), the entire Eight Variable of this study show Cronbachs alpha value which are greater than the recommended value of (0.70) which indicates a comparatively high level of internal consistency in all variables 
Table 1: Result of Reliability and Validity Analysis which shows Cranachs Alpha Value

\begin{tabular}{llcc}
\hline & Variables of study & No. of Items & Cronbachs Alpha \\
\hline & Entrepreneurial orientation & & \\
(a) & Innovativeness & 3 & .853 \\
(b) & Pro-activeness & 3 & .866 \\
(c) & Risk Taking & 4 & .790 \\
(d) & Competitive Aggressiveness & 4 & .870 \\
(e) & Autonomy & 4 & .838 \\
& Innovation performance & 6 & .899 \\
& Firm performance (SMEs) & & \\
(a) & Financial performance & 3 & .864 \\
(b) & Non-financial performance & 4 & .920 \\
\hline
\end{tabular}

The Sum of Percentage Is Not $100 \%$ Due to Rounding.

items that are used in this research study.

\subsection{Correlation Coefficient}

Correlations Coefficients are used to illustrate inter relationships among variables. The correlation results of all variables show that all the variables are highly correlated to each other. The Pearson correlation results indicate in (see Table 4-2).i.e., Mediating variable of this research study is Innovation Performance and Independent Variable of the research study Entrepreneurial Orientation are 0.675 (67\%) correlated, Dependent Variable of this research study Firm Performance and Independent Variable Entrepreneurial Orientation are 0.598 (59\%) correlated, and Mediating Variable Innovation Performance and Dependent Variable Firm Performance are 0.678 (67\%) are Correlated with each other The correlation values between all the Variables less than 0.80 indicate that there is no multico-linearity issue (Jalali et al., 2014). The results of this research study through (Covin et al., 2006), established to an Entrepreneurial Orientation and its all the five-dimensional are positively connected with Innovation Performance to the firms performance. According to Lumpkin and Dess (1996) \& Hughes and Morgan (2007) established an un-equal impact of Entrepreneurial Orientation and innovation performance effect on the firm performance.

\subsection{Regression Analysis}

In this research study we used regression analysis to predict the value of dependent variable which is based on the independent variables values. Linear regression analysis was run for testing the effect of Innovativeness, Pro-activeness, Risk Taking, Competitive aggressiveness and Autonomy on firm performance., independent variable Innovativeness, Pro- activeness, Risk Taking, Competitive aggressiveness and Autonomy on mediator variable (Innovation Performance)and effect of mediating variables (Innovation Performance) on dependent variable (Firm Performance); also Independent variable and Mediating Variable (Innovation Performance) on Firm Performance. This research study finding is consistent with research by Fagerström (2008); Kafayat et al. (2014); Kibera and Muturi (2018); Park et al. (2013).

\subsubsection{Mediation Regression Analysis for En- trepreneurial Orientation and Innovation Performance}

We performed hierarchical regression analyses in order to test the hypothesis formally. Firstly, EO was regressed on Innovation performance. In the first step, control variables are (Firm Size, Firm Age, and Industry) were entered and only the value of their $R^{2}$ is reported, that shows $0.17 \%$ of the Dependent variable innovation performance is explained by the control variables. In the second step, EO was entered and the values of their $R^{2}$, change in $R^{2}$ and beta $(\beta)$ are reported. The value of $R^{2}=0.566$ that shows about $56 \%$ of the variation in Innovation Performance is caused by EO but the remaining $44 \%$ is not captured in this model and needs to be explored. The value of the F-statistic (3.458, sig 0.000) is statistical significant and indicates that the model is fit. The $\delta$ in $\mathrm{R}^{2}$ indicates that, after controlling demographics, the value of $R^{2}$ is significantly affected.

The hypothesis predicts that EO is positively associated Innovation performance. To test These predictions, we regressed Innovation performance on EO (see Table 6).EO heuristic bias $(\beta=0.225, \mathrm{p}<0.000)$ was a significant predictor of Innovation Performance, providing support to $\mathrm{H}_{6}$. 
Table 2: Correlations Coefficient

\begin{tabular}{lccccc}
\hline Variables & Mean & SD & EO & Innovation performance & FP \\
\hline Entrepreneurial Orientation & & & & & \\
& 48.4794 & 9.56317 & 1 & \\
Innovation performance & & & $.675^{* *}$ & 1 \\
& 20.3042 & 3.66143 & .001 & $.678^{* *}$ & \\
Firm Performance & & & $.598^{* *}$ & .000 & 1 \\
\hline
\end{tabular}

**. Correlation is significant at the 0.01 level (2-tailed).

*. Correlation is significant at the 0.05 level (2-tailed)

Table 3: Regression Analysis

\begin{tabular}{lccccc}
\hline Variables & $\beta$ & T Value & P Value & $\mathbf{R}^{2}$ & ${\text { Change in } \mathbf{R}^{2}}^{\text {Step 1 }}$ \\
Control & & & & & \\
Step 2 & & & & & \\
Entrepreneurial Orientation & .225 & 3.223 & .001 & .566 & $.0549^{* *}$ \\
\hline
\end{tabular}

$n=200,{ }^{*} p<0.05,{ }^{* *} p<0.01,{ }^{* *} p<0.001$; Dependent Variable: Innovation Performance.

\subsubsection{Mediation Regression Analysis for Inno- vation Performance and Firm Performance}

We performed hierarchical regression analyses in order to test the hypothesis formally. Firstly, Innovation Performance was regressed on Firm performance. In the first step, control variables (Firm Size, Firm Age, and Industry) were entered and only the value of their Ris reported, that shows $0.5 \%$ of the Dependent variable FP is explained by the control variables. In the second step, Innovation Performance was entered and the values of their $R^{2}$, change in $R^{2}$ and beta $(\beta)$ are reported. The value of $R^{2}=0.379$ that shows about $37 \%$ of the variation in Firm Performance is caused by Innovation Performance but the remaining 63\% is not captured in this model and needs to be explored. The value of the F-statistic $(4.205$, sig 0.000$)$ is statistically significant and indicates that the model is fit. The $\delta$ in $\mathrm{R}^{2}$ indicates that, after controlling for demographics, the value of $R^{2}$ is significantly affected.

The hypothesis predicts that mediating variable Innovation Performance is positively connected with dependent variable Firm performance. To test these Predictions, we regressed firm performance on Innovation Performance (see Table 7).Innovation Performance heuristic bias $(\beta=0.275, \mathrm{p}<0.000)$ was statistically significant predictor for Firm Performance, providing support to $\mathrm{H}_{7}$.

\subsubsection{Mediation Regression Analysis for EO, Innovation Performance \& Firm Perfor- mance}

We performed hierarchical regression analyses in order to test the hypothesis formally. Firstly, EO \& Innovation Performance was regressed on Firm performance. In the first step, control variables (Firm Size, Firm Age, and Industry) were entered and only the value of their $\mathrm{R}$ is reported, that shows $0.5 \%$ of the Dependent variable firm performance is explained by the control variables. In the second step, EO \& Innovation Performance were entered and the values of their $R^{2}$, change in $\mathrm{R}^{2}$ and beta $(\beta)$ are reported. The value of $\mathrm{R}^{2}=(0.460 \& 0.396)$ that shows about $46 \%$ and $39 \%$ of the variation in Firm Performance is caused by EO and Innovation Performance but the remaining 54\% And $61 \%$ is not captured in this model and needs to be explored. The value of the F-statistic (9.273 \& 9.434, $\operatorname{sig} 0.000$ ) is statistical significant and indicates that the model is fit. The $\delta$ in $\mathrm{R}^{2}$ indicates that, after controlling for demographics, the value of $R^{2}$ is significantly affected. The hypothesis predicts that EO \& Innovation Performance is positively associated with Firm performance. To test these predictions, we regressed firm performance on EO \& Innovation Performance (see Table VIII).EO \& Innovation Performance heuristic bias ( $\beta=$ $0.397 \& 0.196, p<0.000)$ was a significant predictor of Firm Performance, providing support Hypothesis 8 \& In Mediation Regression analysis this study shows that 
Table 4: Regression Analysis

\begin{tabular}{lccccc}
\hline Variables & $\beta$ & T Value & P Value & $\mathbf{R}^{2}$ & Change in $\mathbf{R}^{2}$ \\
\hline Step 1 & & & & & \\
Control & & & .005 & & \\
Step 2 & & & & & \\
Innovation Performance & .275 & 3.970 & .000 & .379 & $.0374^{* *}$ \\
\hline$n=200,{ }^{*} p_{i} 0.05,{ }^{* *} p_{i} 0.01,{ }^{* * * *} p_{i} 0.001 ;$ Dependent Variable: Firm Performance.
\end{tabular}

Table 5: Regression Analysis

\begin{tabular}{lccccc}
\hline Variables & $\beta$ & T Value & P Value & $\mathbf{R}^{2}$ & Change in $\mathbf{R}^{2}$ \\
\hline Step 1 & & & & & \\
Control & & & .005 & & \\
Step 2 & & & & & \\
Entrepreneurial Orientation & .397 & 5.994 & .000 & .460 & $.155^{* *}$ \\
Innovation Performance & .196 & 2.937 & .004 & .396 & $.191^{* *}$ \\
\hline
\end{tabular}

$n=200,{ }^{*} p_{i} 0.05,{ }^{* *} p_{i} 0.01,{ }^{* * *} p_{i} 0.001 ;$ Dependent Variable: Firm Performance.

the relationship between Independent dependent and meditating variable is significant so its a partial Mediation.

\section{Summary, Conclusions and Rec- ommendations}

\subsection{Discussion}

This research studys main objective was to establish the role of entrepreneurial orientation and its dimensions on the firm performance (which is financial or non-financial performance) with the mediating role of innovation performance. The study found out that entrepreneurial orientation helps small \& medium enterprises to increased performance. This study also establishes that the major factors that impacts performance of SMEs which includes Innovativeness, Proactiveness, Risk_Taking, Competitive Aggressive \& Autonomy.

This research study also reveals that innovativeness impacts the firm performance of small \& medium enterprises which enable them for market disseminations. The firms persuade inventive ideas and conducting tests when introducing new products and Technological Ideas, developing new technological processes; develop new products and services in SMEs. The Innovation performance generates new value for customers satisfactions and motivation, initiates innovations performance in most situation ahead of their competitors and they are creative in create and scheming resources.

This research study identified that pro-activeness prejudiced the firm performance of SMEs, in large extent because the firms owners identify needs of cur- rent and potential customers and consumers, reallocates its income to compact with budding opportunity and pressure, and monitor market trends to predict future trend. Although from these methods the firm is able to predict or act in response to up-and-coming needs of customers. In that ways and process the firms are able to continually seeks opportunities for new customers and consumers which relate to their current or presents needs or wants. The firms are also capable for anticipating new changes and create competitive advantage.

This research findings also exposed that risk taking impact on firm performance of SMEs to a big amounts the respondents approved to the statement that their firms commit a huge part of their wealth to venture with unsure outcomes, takes heavy borrowing from banks, invest in high-risk goods which guarantee high profits, interrelate a lot with consumers to reveals new opportunity, use risk managing technique to moderate the risks in the firms, decrease the conclusions of risktaking by onward preparation and anticipate every one effect, and handle themselves at some stage in stressful times of firm before they make a risky firm decision they determine whether it is the right decision to make.

This research study also identified that Autonomy refers to the firms capability to make decisions and to continue their activities / actions independently, not including any restrictions from the firm owners and managers. It also shows that strong desire of a person has freedom to develop of their own idea and they can implement it. Several scholars also recommended that autonomy gives power to all players in the firms to motivate them and build their satisfactions to act entrepreneurially, and helps them to improve their firm performance either financial performance or 
non-financial performance. Despite that acknowledgement of autonomy enhances firm performance. This research study also reflects that the Competitive aggressiveness in firms performance is an intensity of effort to better perform production rival, which is characterize by an aggressive attitude and a powerful reaction to competitors proceedings.

\subsection{Conclusions}

In regards to entrepreneurial orientation and its dimensions this research study concludes that its five dimensions have a major contribution toward increased firm performance of small \& medium enterprises which are as follow and discussed. EO plays a vital function in determining the firm performance of SMEs would be recognized. According to above mentioned debate, it can be concluded that an (EO) can be considered as processes, practices, thinking, and decisionmaking activities OR actions which guide firms toward improvement in its products and services \& technology process. The significance of (EO) is to be continued existence and firm development of SMEs through innovation performance roles and functions which are very significance for every small \& medium enterprise.

\subsection{Limitations of the Study}

This research study limitations are on the role play by entrepreneurial orientation to firm performance of small and medium enterprises; which has an exclusive trade environment compared to other countries, dissimilar results would have been predicted if a wider district was investigated to would-be further envoy of SME. This study also focused on other principal factor such as Government policies, political power, environmental factors between others were not enclosed in this study since they were not inside the capacity of study of the investigator. Moreover, the studys dependence on questionnaire presented so far, an additional limitation to the study because the true position would not be established with confidence. This, therefore, complete the studys conclusion and generalization a theme for additional testing. At last, the study composed data as of just a small representation of small and medium enterprises in Islamabad Pakistan, exit out an extra set of regularly significant population. It is consequently recognized that their insertion would have significantly varied some of the studys conclusion.

\subsection{Suggestion for Future Studies}

This study recommends that as like study must too be complete on further cities/countries because their operations are diverse from those intentional in this study. Further studies must be done on other city other than Islamabad, to get out whether it will give up the same information or change. Similar to as Studies might also be done on impact of Entrepreneurial orientation (EO) on business performance in terms of sales growth and profitability of SMEs and all other organizations.

\section{References}

Alvarez, S. A. and Barney, J. B. (2004). Organizing rent generation and appropriation: toward a theory of the entrepreneurial firm. Journal of Business Venturing, 19(5):621635.

Alvarez, S. A. and Busenitz, L. W. (2001). The entrepreneurship of resource-based theory. Journal of management, 27(6):755-775.

Audretsch, D. B. (2002). The dynamic role of small firms: Evidence from the us. Small business economics, 18(1-3):13-40.

Bengesi, K. M. and Le Roux, I. (2014). Strategic entrepreneurial response of small and medium enterprises in developing economies.

Bhuian, S. N., Menguc, B., and Bell, S. J. (2005). Just entrepreneurial enough: the moderating effect of entrepreneurship on the relationship between market orientation and performance. Journal of business research, 58(1):917.

Burgelman, R. A. (1983). A model of the interaction of strategic behavior, corporate context, and the concept of strategy. Academy of management Review, 8(1):61-70.

Covin, J. G., Green, K. M., and Slevin, D. P. (2006). Strategic process effects on the entrepreneurial orientation-sales growth rate relationship. Entrepreneurship theory and practice, 30(1):57-81.

Covin, J. G. and Slevin, D. P. (1989). Strategic management of small firms in hostile and benign environments. Strategic management journal, 10(1):75-87.

do Paço, A. M. F., Ferreira, J. M., Raposo, M., Rodrigues, R. G., and Dinis, A. (2011). Behaviours and entrepreneurial intention: Empirical findings about secondary students. Journal of International Entrepreneurship, 9(1):20-38.

Fagerström, S. (2008). Behavioural finance: The psychological impact and overconfidence in financial markets.

Fernández-Muñiz, B., Montes-Peón, J. M., and VázquezOrdás, C. J. (2009). Relation between occupational safety management and firm performance. Safety science, 47(7):980-991.

Giampiccoli, A., van der Merwe, P., and Saayman, M. (2013). The impact of private game farms on local community development.

Green, K. M., Covin, J. G., and Slevin, D. P. (2008). Exploring the relationship between strategic reactiveness and entrepreneurial orientation: The role of structure-style fit. Journal of Business Venturing, 23(3):356-383. 
Hughes, M. and Morgan, R. E. (2007). Deconstructing the relationship between entrepreneurial orientation and business performance at the embryonic stage of firm growth. Industrial marketing management, 36(5):651-661.

İşeri-Say, A., Toker, A., and Kantur, D. (2008). Do popular management techniques improve performance? evidence from large businesses in turkey. Journal of Management Development, 27(7):660-677.

Jalali, A., Jaafar, M., Talebi, K., and Ab Halim, S. (2014). The moderating role of bridging ties between risk-taking, proactivness and performance: The evidence from iranian smes. International Journal of Business and Management, 9(5):74.

Kafayat, A., Rehman, K. U., and Farooq, M. (2014). Factors effecting corporate cash holding of non-financial firms in pakistan. Acta Universitatis Danubius. OEconomica, 10(3).

Kibera, M. and Muturi, W. (2018). Effect of financial risk management on financial performance of firms listed in the nairobi securities exchange. American Journal of Finance, 3(1):67-88.

Kollmann, T. and Stöckmann, C. (2014). Filling the entrepreneurial orientation-performance gap: The mediating effects of exploratory and exploitative innovations. Entrepreneurship Theory and Practice, 38(5):1001-1026.

Kothari, C. R. (2004). Research methodology: Methods and techniques. New Age International.

Kraus, S., Kauranen, I., and Henning Reschke, C. (2011). Identification of domains for a new conceptual model of strategic entrepreneurship using the configuration approach. Management research review, 34(1):58-74.

Lappalainen, J. and Niskanen, M. (2009). Financial performance of smes-evidence on the impact of ownership structure and board composition. Available at SSRN 1500853.

Lee, C., Lee, K., and Pennings, J. M. (2001). Internal capabilities, external networks, and performance: a study on technology-based ventures. Strategic management journal, 22(6-7):615-640.

Lumpkin, G. T. and Dess, G. G. (1996). Clarifying the entrepreneurial orientation construct and linking it to performance. Academy of management Review, 21(1):135-172.

Lumpkin, G. T. and Dess, G. G. (2001). Linking two dimensions of entrepreneurial orientation to firm performance: The moderating role of environment and industry life cycle. Journal of business venturing, 16(5):429-451.

Madhavan, R. and Grover, R. (1998). From embedded knowledge to embodied knowledge: new product development as knowledge management. Journal of marketing, 62(4):112.

Marfo, E., Chen, L., Xuhua, H., Antwi, H., Yiranbon, E., et al. (2015). Corporate social responsibility: driving dynamics on firms profitability in ghana. International Journal of Academic Research in Accounting, Finance and Management Sciences, 5(3):116-132.
McClelland, D. (1961). The achieving society van nostrand. Princeton, NJ.

Miller, D. (1983). The correlates of entrepreneurship in three types of firms. Management science, 29(7):770-791.

Miller, D. and Friesen, P. H. (1982). Innovation in conservative and entrepreneurial firms: Two models of strategic momentum. Strategic management journal, 3(1):1-25.

Mirela, B. (2008). Innovation-the characteristic tool of entrepreneurs. Economic Science Series, 17(4):135-138.

Mugenda, O. M. and Mugenda, A. G. (2003). Research methods. Quantitative and qualitative approaches, pages 46-48.

Park, C. W., Eisingerich, A. B., Pol, G., and Park, J. W. (2013). The role of brand logos in firm performance. Journal of Business Research, 66(2):180-187.

Prajogo, D. I. and Sohal, A. S. (2006). The integration of tqm and technology/r\&d management in determining quality and innovation performance. Omega, 34(3):296-312.

Rauch, A., Wiklund, J., Frese, M., and Lumpkin, G. T. (2004). Entrepreneurial orientation and business performance: Cumulative empirical evidence. In 23rd Babson College Entrepreneurship Research Conference. Glasgow, UK.

Rose, C. (2007). Does female board representation influence firm performance? the danish evidence. Corporate Governance: An International Review, 15(2):404-413.

Schumpeter, J. A. (1939). Business cycles: a theoretical, historical, and statistical analysis of the capitalist process. McGraw-Hill New York.

Short, J. C., McKelvie, A., Ketchen Jr, D. J., and Chandler, G. N. (2009). Firm and industry effects on firm performance: A generalization and extension for new ventures. Strategic Entrepreneurship Journal, 3(1):47-65.

Van Gelderen, M., Van de Sluis, L., and Jansen, P. (2005). Learning opportunities and learning behaviours of small business starters: relations with goal achievement, skill development and satisfaction. Small Business Economics, 25(1):97-108.

Venkatraman, N. and Ramanujam, V. (1986). Measurement of business performance in strategy research: A comparison of approaches. Academy of management review, 11(4):801814.

Wang, C. L. (2008). Entrepreneurial orientation, learning orientation, and firm performance. Entrepreneurship theory and practice, 32(4):635-657.

West, M. A. and Anderson, N. R. (1996). Innovation in top management teams. Journal of Applied psychology, 81(6):680.

Wiklund, J. and Shepherd, D. (2005). Entrepreneurial orientation and small business performance: a configurational approach. Journal of business venturing, 20(1):71-91. 
Zahra, S. A. and Covin, J. G. (1993). Business strategy, technology policy and firm performance. Strategic management journal, 14(6):451-478.

Zaltman, D. (1973). Holbeck (1973). communication strategies for change and innovation. Communication in complex orga- nizations: A relational Approach. USA: Harcout Brace College Publishers.

Zehir, C., Can, E., and Karaboga, T. (2015). Linking entrepreneurial orientation to firm performance: the role of differentiation strategy and innovation performance. Procedia-Social and Behavioral Sciences, 210:358-367. 